\title{
PERCEPÇÃo DE ESTUdANTES DO ENSINO MÉdIO DE UMA ESCOLA PÚBLICA SOBRE A APRENDIZAGEM DA TABELA PERIÓDICA
}

\section{ARTIGO ORIGINAL}

SILVA, Antonio Denilson Leandro da ${ }^{1}$

SILVA, Antonio Denilson Leandro da. Percepção de estudantes do Ensino Médio de uma escola pública sobre a aprendizagem da tabela periódica. Revista Científica Multidisciplinar Núcleo do Conhecimento. Ano 05, Ed. 11, Vol. 21, pp. 91100. Novembro de 2020. ISSN: 2448-0959, Link de acesso: https://www.nucleodoconhecimento.com.br/educacao/tabela-periodica

\section{RESUMO}

O ensino de química, muitas vezes baseados na mera transmissão de conteúdo sem uma precisa contextualização, acaba provocando um desinteresse por parte de muitos estudantes acerca desse campo da ciência, pois consideram uma disciplina de difícil aprendizagem. Assim, ao ensinar o conteúdo sobre Tabela Periódica dos Elementos (TPE) de uma maneira eficaz, isso permite aos estudantes a possibilidade de compreender melhor os demais assuntos que estão relacionados diretamente a TPE. Desse modo, coletar informações que permitam valorizar os conhecimentos prévios dos educandos, bem como fazê-los sujeitos protagonistas na produção de saberes, apesar de não ser tão simples e fácil, mas que é essencial dentro do contexto das novas perspectivas do ensino de química. Assim, objetivamos com este trabalho conhecer a concepção dos estudantes sobre a aprendizagem da TPE, visando identificar na contribuição dos estudantes, aspectos relevantes que auxiliem na melhoria e qualidade do Ensino de Química. Os resultados obtidos nesta pesquisa nos revelam o quão importante é ouvir a opinião dos estudantes quanto as

${ }^{1}$ Graduado em Ciências Naturais com Habilitação em Química pela Universidade do Estado do Pará (UEPA). Especialista em Ensino de Química pela Faculdade Faveni. 
metodologias adotadas pelo professor em sala de aula, uma vez que este são o foco dentro do processo de ensino-aprendizagem.

Palavras-Chave: Ensino de Química, Tabela Periódica, ensino-aprendizagem.

\section{INTRODUÇÃO}

Ensinar não é uma tarefa tão simples quanto muitos imaginam ser. Isso requer dedicação e critérios metodológicos essenciais para possibilitar a aprendizagem. Desse modo, repassar conhecimentos de Química, sendo esta pouco atraente aos olhos de muitos alunos, torna-se um desafio ainda muito maior, pois enquanto docentes precisamos cativar o educando para que perceba que este campo da ciência está diretamente ligado ao seu cotidiano.

As Diretrizes Curriculares Nacionais para o Ensino Médio (DCNEM), que compreende a área de Ciências da Natureza, Matemática e suas Tecnologias, estabelecem que "Como campo disciplinar, a Química tem sua razão de ser, sua especificidade, seu modo de interrogar a natureza, controlar respostas por meio de instrumentos técnicos e de linguagem peculiares, identificando as pessoas que os dominam como químicos ou educadores químicos."(p. 104).

Muitos discentes ao ingressar no Ensino Médio (EM) chegam com uma visão de que a Química é uma disciplina difícil, com muitos cálculos, fórmulas, etc., portanto, cabe ao professor a partir do desenvolvimento das aulas quebrar esse paradigma, levandoos a compreender a importância dessa ciência para o incremento de novas tecnologias, contribuindo com as necessidades da sociedade moderna.

A melhoria da qualidade do ensino de Química deve ser alcançada através uma proposta metodológica que possibilite aos alunos a experimentação como uma forma de equipará-la a realidade do dia a dia. Este tipo de metodologia possibilita ao aprendiz uma visão do mundo de uma forma cognitiva pela dualidade entre a teoria e a prática, pois quanto mais integrada mais concreta se torna aprendizagem. (BERNADELLI, 2004 Apud ANDRADE e BARBOSA, 2017, p. 9). 
Ainda de acordo com os Parâmetros Curriculares Nacionais do Ensino Médio (PCNEM) "é preciso objetivar um ensino de Química que possa contribuir para uma visão mais ampla do conhecimento, que possibilite melhor compreensão do mundo físico e para a construção da cidadania" (BRASIL, 2002, p. 32).

Nesse sentido, podemos afirmar que o uso da linguagem simbólica em Química é fundamental para explicitar um fenômeno decorrente e, o estudo da Tabela Periódica dos Elementos (TPE) é primordial dentro do estudo e ensino deste campo da ciência.

Tudo o que estiver relacionado a Química tem como base a TPE, pois nesta, encontram-se organizados todos os elementos químicos que constituem todo e qualquer tipo de matéria que existe na natureza, sejam naturais ou artificiais. Através do seu estudo compreendemos as características de todos os elementos e como estas estão correlacionadas aos 18 grupos (colunas) e aos 7 períodos (linhas) nela contidos. Assim, ressaltamos que tal estudo é a base de todos os conhecimentos químicos posteriores.

Ao ensinar TPE o professor deve usar de recursos metodológicos que permitam ao discente ter uma visão holística do conteúdo estudado. Sendo assim, é preciso dar sentido ao conhecimento transmitido, levando em conta a aplicação destes elementos nos objetos que nos cercam diariamente.

De acordo com Trassi et al. (2001, p. 1335): "O Ensino da Química e, em particular, o tema Tabela Periódica, praticado em um grande número de escolas, está muito distante do que propõe, isto é, o ensino atual privilegia aspectos teóricos de forma tão complexa que se torna abstrato para o educando."

Portanto, cabe ao professor envolver os estudantes de forma em que eles se sintam protagonistas na aquisição do conhecimento químico, selecionando os conteúdos mais relevantes, a aplicação destes elementos e sua relação com os demais conteúdos.

Ressalta-se, portanto, que esta pesquisa é essencial para compreendermos a percepção dos estudantes da $1^{\underline{a}}$ série do EM acerca da aprendizagem da TPE, tendo 
em vista que eles são os principais sujeitos capazes de melhor contribuir para com a metodologia do professor.

Não podemos desqualificar as concepções dos estudantes, assim, valorizar seus conhecimentos prévios são uma forma assegurar seu protagonismo na produção de novos saberes.

Neste artigo, perceberemos nas respostas dos alunos, ideias interessantes que 0 docente pode acolher a fim de melhorar a sua prática pedagógica. Assim, objetivamos com este trabalho conhecer a concepção dos estudantes sobre a aprendizagem da TPE, visando identificar na contribuição destes aspectos relevantes que auxiliem na melhoria e qualidade do Ensino de Química.

\section{MATERIAL E MÉTODOS}

O desenvolvimento deste trabalho é resultado de uma pesquisa descritiva, baseada em dados provenientes de questionário, cujas perguntas remetem ao ensino da disciplina Química, especificamente, sobre o estudo da Tabela Periódica dos Elementos, através de uma abordagem quali-quantitativa. O referido questionário foi respondido por alunos do Ensino Médio da Escola Estadual "Padre Marino Contti", localizada no município de Mãe do Rio, região nordeste do estado do Pará, distante 194 km da capital Belém. Trata-se de uma escola de porte considerável, possuindo mais de 1500 alunos matriculados, oriundos da zona urbana (em torno de $60 \%$ do total de alunos) e de agrovilas próximas da sede do município ( $40 \%$ do total de alunos).

A pesquisa envolveu estudantes de uma turma da primeira série do Ensino Médio que têm 29 alunos matriculados. Os sujeitos da pesquisa têm idade entre 14 a 17 anos, e a maioria deles realizaram todo o Ensino Fundamental em escolas públicas do município.

Importante ressaltar que, antes da aplicação do questionário de pesquisa foi desenvolvida uma aula dinâmica, interativa, onde os sujeitos através de questões 
propostas pelo professor iam sendo envolvidos. Isso foi fundamental porque até os estudantes tímidos foram se envolvendo e participando ativamente da aula. Sempre apresentava questões surpresas para eles e cronometrava, aqueles que conseguissem responder dentro do tempo estipulado ganhavam pontuação extra, e a maioria conseguia fazer as questões.

Os dados foram obtidos através da aplicação de um questionário de pesquisa (ver anexo), com perguntas fechadas e abertas relacionadas com o conteúdo e aprendizagem da Tabela Periódica dos Elementos. Em seguida, os dados foram organizados em gráficos e tabelas.

\section{RESULTADOS E DISCUSSÃO}

Para quantificar a eficiência da proposta metodológica as respostas foram tabuladas e exibidas abaixo em forma de gráficos, apresentando os resultados. A primeira pergunta era "A tabela periódica é um assunto de difícil compreensão?"

Gráfico 1: Quanto a compreensão da Tabela Periódica

\section{Compreensão da Tabela Periódica}

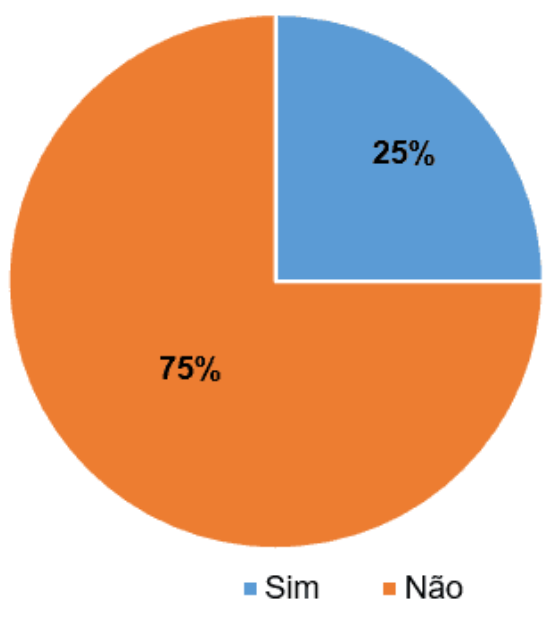

Fonte: autor. 
Fica evidente, através deste gráfico que o estudo da TPE não é difícil compreensão, $75 \%$ deles conseguiram de certa maneira captar as informações fundamentais sobre o assunto estudado. Isso está inteiramente relacionado ao dinamismo das aulas em foram desenvolvidas este estudo, percebia-se que os estudantes estudavam em casa, vinham mais motivados para aula. Embora, percebamos que 25\% afirmaram ser um assunto de difícil compreensão, isso se justifica muitas vezes por uma base pouco trabalhada no ensino fundamental, ou mesmo porque a metodologia trabalhada não atendeu aos seus anseios de aprendizagem. Podemos considerar de certa forma a aprendizagem pelos dados coletados nesta pergunta.

A questão seguinte foi: A metodologia adotada pelo seu professor em relação ao assunto da tabela periódica foi eficaz para você aprender o conteúdo?

Gráfico 2: Sobre metodologia e aprendizagem da TPE

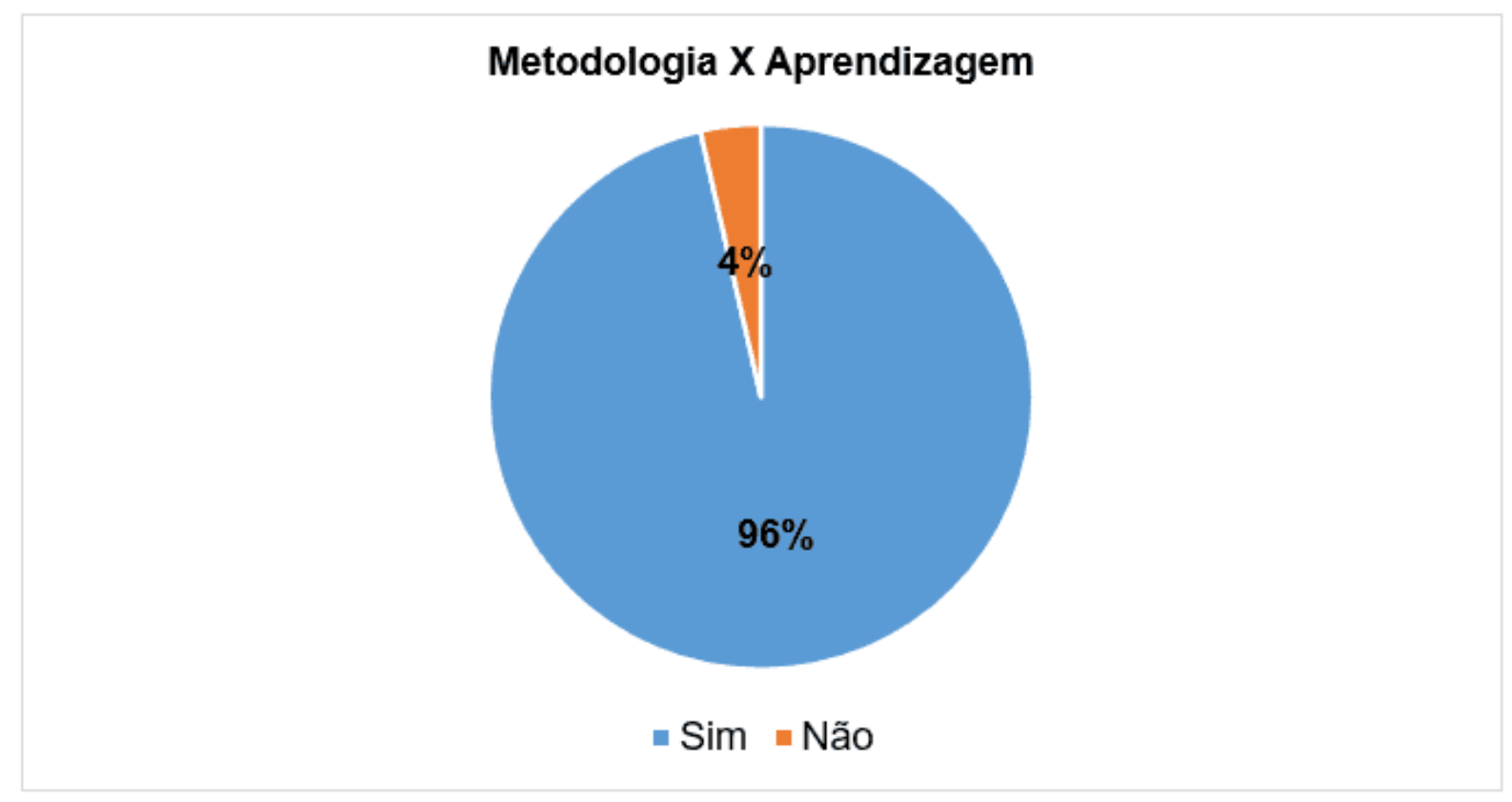

Fonte: autor

Através da análise dos dados referentes a esta questão, podemos inferir que, a metodologia desenvolvida pelo professor foi essencial para a aprendizagem do assunto abordado, pois $96 \%$ afirmaram que aprenderam e apenas $4 \%$ disseram não ter sido suficiente para adquirir o conhecimento. Nesse sentido, é essencial que o 
professor desenvolva um estudo que propicie a todos os discentes habilidades de compreensão, através de uma contextualização. Sobre isso, as DCNEM afirmam que:

Muitas são as demandas para que a educação escolar - muito mais do que substituir um conteúdo por outro - propicie a compreensão das vivências sociais, com enfoque significativo dos conhecimentos historicamente construídos. Isso não pode estar dissociado da ideia de abordagem temática que, permitindo uma contextualização aliada à interdisciplinaridade, considere as duas perspectivas mencionadas, proporcionando o desenvolvimento dos estudantes. (BRASIL, 2006, p. 108-109).

A terceira pergunta aborda a seguinte questão: As questões desafio desenvolvidas em sala de aula estimularam você a buscar aprender mais sobre a Tabela Periódica?

Gráfico 3: Sobre as questões desafio e aprendizagem da TPE

\section{Questões desafio x Aprendizagem}

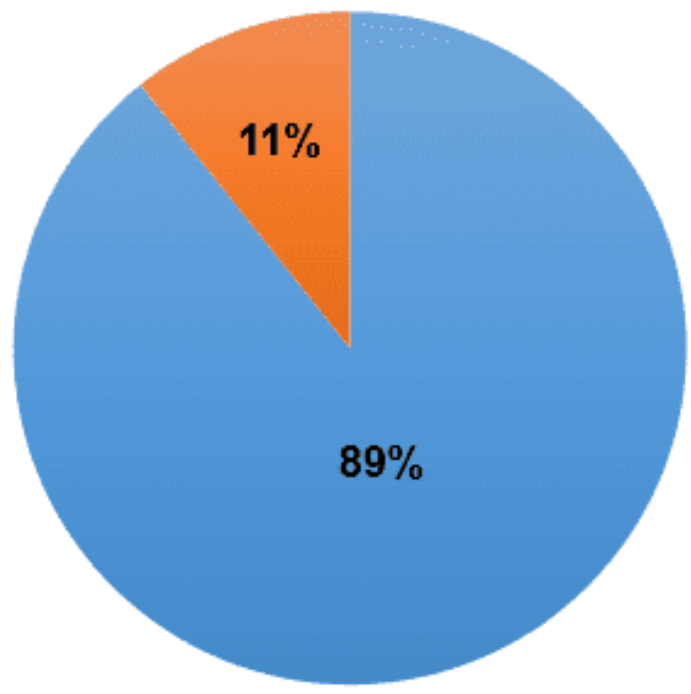

$$
\text { -Sim } \text { Não }
$$

Fonte: autor

Interessante notar que, $89 \%$ dos discentes afirmaram que as questões desafio foram fundamentais, serviram como estímulo para que buscassem aprender mais. Isso evidencia uma boa estratégia metodológica que visa gerar aprendizagem que não visa 
o "decoreba", mas que figura um meio onde o protagonismo estudantil é essencial. Em contrapartida, 11\% afirmaram essa técnica não ser suficiente para apender, é claro que muitas vezes uma metodologia não alcança a todos igualitariamente, pois, alguns têm mais dificuldade no processo de busca pelo conhecimento.

A escolha do método adotado pelo educador pode refletir em resultados positivos e satisfatórios na aprendizagem, neste caso, dando ênfase à Educação em Química. Outro aspecto importante no processo educativo são as relações que se estabelecem entre professores e alunos, geralmente num caráter de cumplicidade e camaradagem. (FREIRE, 1996 apud LEÃO; DEL PINO e OLIVEIRA, 2017, p. 3).

A terceira questão com o seguinte teor: se você fosse professor de Química, que estratégias usaria para ensinar Tabela Periódica ao seus/suas alunos(as)?

Nessa questão a proposta era trazer visão do estudante sob a ótica de melhorar o ensino de química, colocando ele como sujeito central dentro da perspectiva de ensino e aprendizagem. Desse modo, destacarei a seguir algumas respostas, agrupando aquelas que tem semelhanças entre si, para evitar descrever todas as respostas.

Organizando as respostas, percebemos que um grupo de alunos destacou que utilizariam "animações gráficas, videoaulas, aplicativos apropriados para celular e atividades para casa para reforçar a aprendizagem". Em outro conjunto de respostas obtivemos as seguintes contribuições: "usaria dinâmicas em grupos para estimular a interação da classe, jogos, torneios periódicos, aulas práticas, desafios." Além disso, alguns complementaram a resposta afirmando que "o importante é fazer com que o aluno entenda alguns métodos básicos da matéria." Em contrapartida, parte dos alunos afirmaram que "usariam o livro, uma tabela periódica ilustrada, solicitava que seus alunos desenhassem a tabela periódica, atividades de pesquisa", tudo isso para alavancar a aprendizagem.

Freitas Filho e Celestino, afirmam que:

A aprendizagem de conceitos que uma pessoa adquire de um determinado conhecimento acontece a partir do momento em que ele é capaz de dotar o significado de um material ou informação que lhe é 
apresentado, isto é, quando se compreende esse material, podendo a partir disso, traduzi-lo para suas palavras. (2010, p. 189).

Mediante tal contexto, valorizar as concepções prévias dos alunos por meio da escuta e interação, é salutar para uma aprendizagem significativa, rompendo com o tradicionalismo técnico de transmissão do conhecimento científico.

Desse modo, aprender química não é copiar ou reproduzir conceitos reais, mas levar o educando a reelaborar as ideias sob a ótica da realidade conteúdos que se pretende aprender. (KLINGER e BARICCATTI, S/D).

O estudo da Tabela Periódica é importante para compreendermos os diversos produtos e os fenômenos químicos que ocorrem na natureza?

Quanto a esta pergunta, é válido ressaltar que todos os sujeitos envolvidos na pesquisa afirmaram que a Tabela Periódica é fundamental para compreendermos os fenômenos da natureza e todos os produtos que existem fabricados industrial ou manualmente. Entre as justificativas destaco abaixo algumas:

"Os elementos são usados como matéria prima de diversos produtos;"

"Porque sem as anotações, fórmulas e a tabela não seríamos capazes de entender a natureza."

"A Tabela Periódica nos ajuda a saber quais elementos existem no planeta, nos ajuda observar mais cada coisa que acontece na natureza e a entender os fenômenos que ocorrem todos os dias."

"Porque nos incentiva a aprender mais sobretudo que a natureza tem, e sobre tudo o que ela pode nos oferecer de bom e as coisas incríveis que ela faz, então seria um dever todos aprender sobre ela."

Apesar de ainda não ter um estudo mais aprofundado acerca da TPE, percebemos o quão suas respostas demonstram ter ligação direta com aquilo que este estudo nos proporciona. Dessa forma, de acordo com Mortimer (apud FILHO e CELESTINO, 
2010, p. 189) ao menos duas características são comuns em todas as vertentes: "(1) a aprendizagem se dá através do ativo envolvimento do aprendiz na construção do conhecimento; (2) as ideias prévias dos estudantes desempenham um papel importante no processo de aprendizagem."

\section{CONCLUSÃO}

Os resultados obtidos nesta pesquisa nos revelam o quão importante é ouvir a opinião dos estudantes quanto as metodologias adotadas pelo professor em sala de aula, uma vez que este são o foco dentro do processo de ensino-aprendizagem. Desse modo, percebemos o quanto foi fundamental a dinâmica do uso de desafios durante as aulas para viabilizar a participação e a efetivação do conhecimento em trânsito sobre a tabela periódica dos elementos.

Outro ponto, que merece atenção, foi a contribuição dos estudantes quando colocados como "professores", todos de alguma forma deram seu parecer, expressaram a sua "forma de ensinar" e isso é essencial para nós docentes em atividade, pois podemos acolher essas ideias e aplica-las durante nossas aulas, para melhorar a aprendizagem em química.

Enfim, esta pesquisa nos leva a valorizar também, o conhecimento do prévio do aluno. Levar em conta suas contribuições implica dar a ele a oportunidade de colaborar com a metodologia adotada pelo professor, dá voz ao aluno é permitir o protagonismo destes enquanto sujeitos dotados de conhecimentos adquiridos ao longo do seu desenvolvimento intelectual.

\section{REFERÊNCIAS}

ANDRADE, E. S.; BARBOSA, P. S. Tabela Periódica: reconhecimento dos elementos na prática. Faculdade de Educação e Meio Ambiente (FAEMA). Ariquemes - RO, 2017. 
BRASIL. Ministério da Educação, Secretária de Educação Básica. Orientações Curriculares para o ensino médio: volume 2. Ciências da natureza, Matemática e suas Tecnologias /Secretária de Educação Básica. Brasília: 2006. 135p.

BRASIL. Ministério da Educação (MEC), Secretaria de Educação Média e Tecnológica (Semtec). PCN + Ensino médio: orientações educacionais complementares aos Parâmetros Curriculares Nacionais - Ciências da Natureza, Matemática e suas Tecnologias. Brasília: MEC/Semtec, 2002.

FREITAS FILHO, J. R.; CELESTINO, R. M. C. S. Investigação da construção do conceito de reação química a partir dos conhecimentos prévios e das interações sociais. Ciências \& Cognição, 2010; V. 15(1), p. 187-198.

KLINGER, M. A.; BARICCATTI, R. Práticas pedagógicas em cinética química. Disponível em: http://www.gestaoescolar.diaadia.pr.gov.br/arquivos/File/producoes_pde/artigo _miro_alfonso_klinger.pdf. Acesso em: 28 de junho de 2019.

LEÃO, M. F.; DEL PINO, J. C.; OLIVEIRA, E. C. A Tabela Periódica dos Elementos químicos contidos nos alimentos: uma maneira de promover aprendizagens com significado na educação de jovens e adultos. Aprendizagem Significativa em Revista/Meaningful Learning Review. V.7(2), pp. 01-17, 2017.

TRASSI, R.C.M, et al. Tabela Periódica interativa: "Um estímulo à compreensão", Acta Scientiarum, Maringá, v. 23, n. 6, p. 1335-1339, 2001.

Enviado: Outubro, 2020.

Aprovado: Novembro, 2020. 